\title{
Tyrosine kinase inhibitor sensitive PDGFRA mutations in GIST: Two cases and review of the literature
}

\author{
Pieter A. Boonstra ${ }^{1}$, Jourik A. Gietema1, Albert J.H. Suurmeijer ${ }^{2}$, Matthew R. \\ Groves $^{3}$, Fernando de Assis Batista ${ }^{3}$, Ed Schuuring ${ }^{2}$ and Anna K.L. Reyners ${ }^{1}$ \\ ${ }^{1}$ University of Groningen, University Medical Center Groningen, Department of Medical Oncology, Hanzeplein, Groningen, \\ The Netherlands \\ 2 University of Groningen, University Medical Center Groningen, Department of Pathology, Hanzeplein, Groningen, The \\ Netherlands \\ ${ }^{3}$ University of Groningen, Faculty of Science and Engineering, Antonius Deusinglaan, Groningen, The Netherlands \\ Correspondence to: Anna K.L. Reyners, email: a.k.l.reyners@umcg.nl
}

Keywords: GIST; PDGFRa mutation; circulating tumor DNA; ddPCR; non-D842V

Received: January 21, $2017 \quad$ Accepted: October 30, $2017 \quad$ Published: November 26, 2017

Copyright: Boonstra et al. This is an open-access article distributed under the terms of the Creative Commons Attribution License 3.0 (CC BY 3.0), which permits unrestricted use, distribution, and reproduction in any medium, provided the original author and source are credited.

\section{ABSTRACT}

Gastrointestinal stromal tumors (GISTs) are rare mesenchymal malignancies of the gastrointestinal tract. Most GISTs harbor a c-KIT $(\mathbf{8 0} \%)$ or a PDGFRa $(\mathbf{1 0} \%)$ mutation that leads to constitutive activation of the tyrosine kinase receptor. Response to treatment with tyrosine kinase inhibitors (TKIs) is dependent on mutational status of the tumor. The most common mutation in PDGFRa, D842V, is known to be imatinib resistant. Almost all other PDGFRa mutations are imatinib sensitive. We describe two patients with a PDGFRa exon 18 mutated GIST responding to treatment with TKIs. One of these patients has a p.M844_S847 deletion, not previously described in relation with TKI treatment response. Mutations in circulating tumor DNA were detectable with digital droplet PCR in serial plasma samples taken during treatment and correlated with treatment response of both patients. Computer 3D-modeling of the PDGFRa kinase domain of these two variants revealed no direct interference in imatinib or sunitinib binding and no effect in its activity in contrast to the reported structure of the imatinib resistant $\mathrm{D} 842 \mathrm{~V}$ mutation.

An overview is given of the literature regarding the evidence of patients with different PDGFRa mutated GISTs on response to TKIs. The findings emphasize the use of mutational analysis in GIST to provide patients personalized treatment. Detection of mutations in plasma is feasible and can provide real-time information concerning treatment response. We suggest to register GIST patients with these uncommon mutations in a prospective international database to understand the tumor biology and obtain more evidence of such mutations to predict treatment response.

\section{INTRODUCTION}

Gastrointestinal stromal tumors (GISTs) are rare mesenchymal malignancies of the gastrointestinal tract with an incidence of 10 cases per million people [1]. About $50 \%$ of GIST arises in the stomach, $30 \%$ in the small intestine and $20 \%$ in other parts of the gastrointestinal tract [2]. Tumors originate from the interstitial cells of Cajal (or its precursor cells), the smooth muscle pacemaker cells. Constitutively activating mutations in the genes coding for the tyrosine kinase receptors KIT or platelet derived growth factor alpha (PDGFR $\alpha$ ) play a crucial role in the biology of these tumors [3]. Approximately $80 \%$ of GIST harbor mutations in KIT, $10 \%$ in PDGFR $\alpha$. The remaining part are wild type, has a BRAF mutation or inactivation of the SDH complex. KIT exon 11 mutant tumors can occur anywhere in the gastrointestinal tract, whereas PDGFR $\alpha$ mutant tumors arise primarily in the stomach, mesentery and omentum. KIT exon 9 mutant tumors are mostly found in the small intestine [4]. 
Surgery is the only curative treatment and treatment of choice when feasible. Patients with irresectable tumors due to local advancement or metastatic disease can be treated with imatinib mesylate, a KIT selective tyrosine kinase inhibitor (TKI) in neo-adjuvant and palliative setting. Response on systemic treatment is strongly dependent on mutational status of the tumor. Patients with an imatinib-sensitive mutation have a response or stable disease for a median time of 27 months [5]. When imatinib treatment fails, second line treatment with sunitinib and third line treatment with regorafenib is available [6]. Resistance in patients who have an imatinib sensitive primary mutation occurs often as a result of secondary mutations in the tumor that develop during treatment [7]. After potentially curative surgery, patients with PDGFR $\alpha$ mutations and those with wild-type GIST have a lower risk of recurrence than patients with KIT mutations [8]. Once recurrences occur, the most common PDGFR $\alpha$ mutation in exon $18(\mathrm{D} 842 \mathrm{~V})$ is known to be resistant to imatinib treatment. But not all GISTs with a mutation in exon 18 of the PDGFR $\alpha$ gene are resistant to treatment with a TKI. Since the introduction of mutation analysis in biopsies of GIST tumors, it is known that specific PDGFR $\alpha$ mutations appear to be imatinib sensitive [9]. Response to therapy is generally evaluated by radiological imaging. Recent advances in molecular biology enable the detection of tumor mutations in circulating tumor DNA (ctDNA) in plasma. This plasma mutational load can reflect the treatment response and current disease state [10].

Two patients with various PDGFR $\alpha$ deletions who responded on TKI treatment are described and serial plasma samples of both patients were analyzed with digital droplet PCR (ddPCR). Finally, an overview of literature concerning PDGFR $\alpha$ mutations in GIST is presented.

\section{Clinical summary patient 1}

A 76-year old man was referred with a large abdominal tumor suspected for GIST. His WHOperformance score at first presentation was 3 , being bed bound for the majority of the day. CT and FDG-PET scan showed a $29 \mathrm{~cm}$ large, irresectable tumor without evidence of metastases (Figure 1A). Mutation analysis on the performed biopsy specimen confirmed the diagnosis GIST with a mutation in exon 18 of PDGFR $\alpha$ (NM_006206.5: c.2531_2542del; p.(M844-S847del)). Treatment with imatinib $400 \mathrm{mg}$ once daily was initiated in a neo-adjuvant setting. After one week he reported a clinical relevant benefit by disappearance of nausea and increasing energy levels. On the CT-scans performed every three months, stable disease was seen during one year of treatment. Based on a growing nodule (Figure $1 \mathrm{~B})$, progression was suspected and surgical resection of the tumor was considered. However, progression with peritoneal metastasis was seen on the following CT scan three months thereafter. Surgery with curative intent was
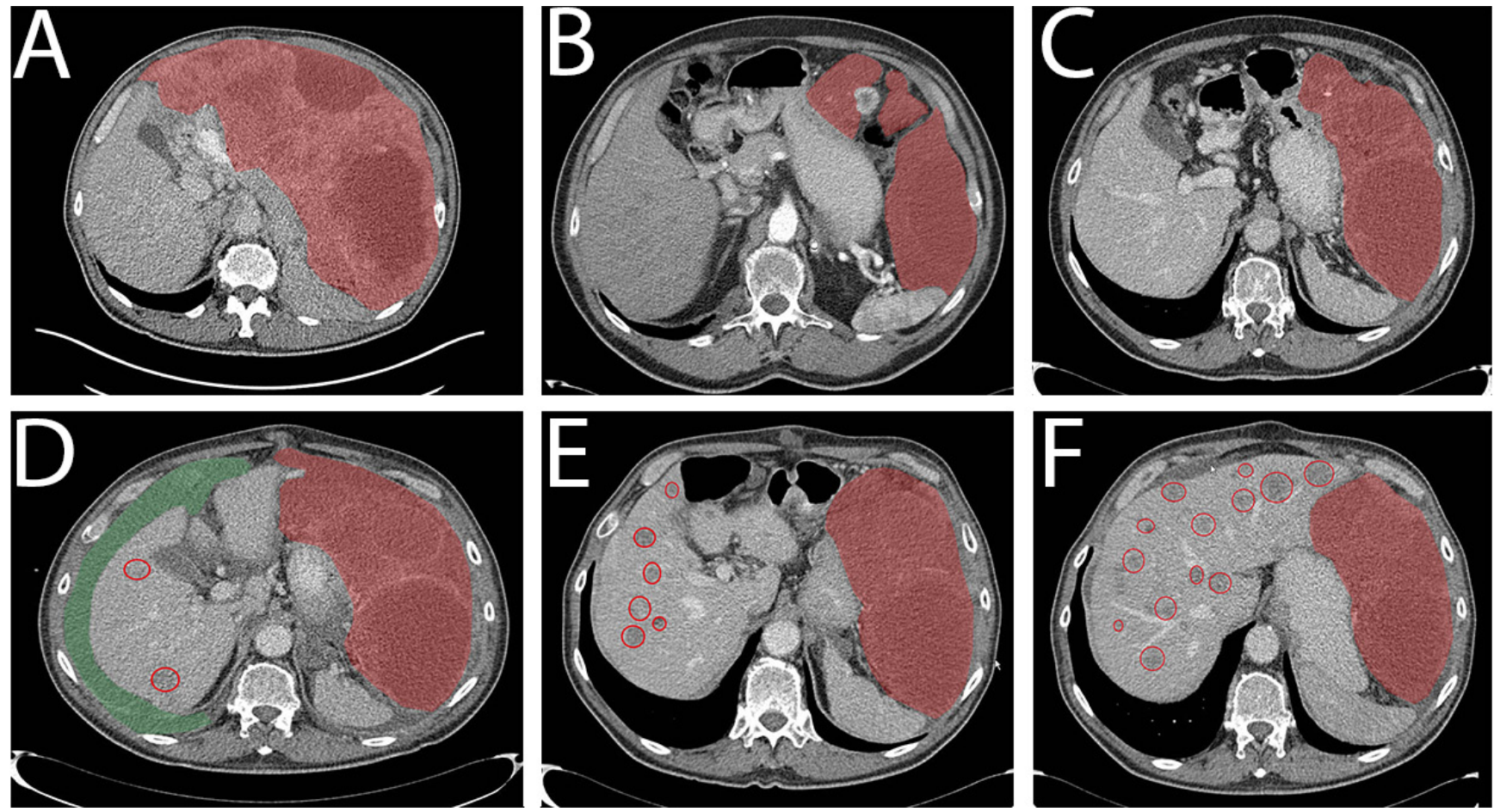

Figure 1: CT images of patient 1. Primary GIST (red area), liver metastases (red circles) and ascites (green) are indicated. A. Pretreatment scan. B. After 12 months imatinib treatment, growing nodule. Start sunitinib. C. 6 months on sunitinib, stable disease. D. One year sunitinib. Progression. Ascites, liver metastasis. Start regorafenib. E. 3 months regorafenib, stable disease. Demarquation of the liver metastasis is seen as response on therapy. F. 6 months regorafenib, progression, more liver metastases are seen. 
no longer feasible and 15 months after start of imatinib, treatment was switched to second line treatment with sunitinib $37.5 \mathrm{mg}$ daily. The patient responded during one year on sunitinib (Figure 1C), until he was admitted to the hospital with malaise and ascites based on disease progression (Figure 1D). He recovered after drainage of ascites. A biopsy of a progressive nodule was performed and treatment with regorafenib (160mg daily for 3 out of 4 weeks) was started. With this regimen stable disease during 5 months was obtained (Figure 1E). He died one month after stopping treatment with regorafenib due to progressive disease (Figure 1F), no clinical benefit was reached with a re-challenge of imatinib. Plasma samples were available during treatment with regorafenib and $4^{\text {th }}$ line imatinib. An increase in mutational copies $/ \mathrm{ml}$ is seen between stable disease (Figure 1E) and progression (Figure 1F) of 180 to 850 mutant copies/ml (Figure 3A). At the last visit to the outpatient clinic (two weeks before death), mutant copies were 4767 copies/ml (month 33).

In total, this patient responded or had stable disease according to RECIST criteria for 32 months on several tyrosine kinase inhibitors. Mutation analysis performed on the progressive tumor nodule before start of regorafenib showed the same p.(M844_S847del) (c.2531_2542del) mutation in exon 18 of PDGFR $\alpha$ as detected in the primary tumor, whereas no additional mutations were found in exon 12 and 14 of PDGFRA nor in exon 9, 11, 13, 14, 17 of KIT (the average coverage is $\sim 2000$ reads in tumor DNA with neoplastic content of $80 \%$ ). Detection of the primary mutation in plasma reflected the clinical course of the disease in this patient.

\section{Clinical summary patient 2}

A 76-year old woman was referred for analysis of abdominal pain. A CT scan showed a large abdominal tumor (diameter $25 \mathrm{~cm}$ ) with multiple liver metastases (Figure 2A and 2B). Biopsy of a liver metastasis showed a CD117 positive tumor, characteristic for GIST. Mutational analysis showed no mutation in KIT, PDGFR $\alpha$ analysis was not performed at the time.

Treatment with imatinib $400 \mathrm{mg}$ daily was initiated and after ten days she had clinical benefit. She tolerated the treatment well and a partial response was seen on the CT-scan performed every 3 months (Figure 2C and 2D). After 30 months of treatment progression of the primary tumor as well as the liver metastases was seen (Figure 2E and $2 \mathrm{~F}$ ). Additional mutation analysis was performed on the biopsy taken at diagnosis and revealed a PDGFR $\alpha$ exon 18 (NM_006206.5: c.2527_2538del; p.(I843_ D846del)) mutation (the average coverage is $\sim 2500$ reads in tumor DNA with neoplastic content of $95 \%$ ). Treatment was continued with increased dosage of imatinib $400 \mathrm{mg}$ twice daily and the patient tolerated this dosage, yet no clinical and radiological response was seen (progressive lesions on CT-scan after 3 months treatment, Figure $2 \mathrm{G}$ and $2 \mathrm{H}$ ). Two months after the treatment was switched to sunitinib $37.5 \mathrm{mg}$ daily the patient continued to deteriorate and she died 36 months after the initial diagnosis. A tissue biopsy of a progressive lesion was not available to evaluate the secondary mutational status. Blood samples for ctDNA analysis (Figure 3B) were first drawn after 16,5 months of treatment with imatinib $400 \mathrm{mg}$ (6 mutant copies $/ \mathrm{ml}$ ). The mutant copies level remained stable until progressive disease was detected at the CT scan at 30 months. After initiation of imatinib 400mg twice daily an increase in mutant copies ( 5 to $275 / \mathrm{ml}$ ) was detected. The mutational level continued to rise to 852 mutant copies/ $\mathrm{ml}$ corresponding with progressive disease on the CT scan performed at 33 months. After initiation of sunitinib treatment, a decrease in mutant copies (208 mutant copies/ $\mathrm{ml}$ ) was measured. Unfortunately, no further samples were available for analysis since the patient deceased after 2 months.

\section{Mutational analysis}

For mutational analysis, DNA was extracted from formalin-fixed, paraffin-embedded (FFPE) tumor tissue using the Cobas DNA extraction kit (Roche, Basel, Switzerland). Next generation sequencing (NGS) analysis using the University Medical Center Groningen oncopanel on the Ion-Torrent platform (Thermo Fischer Scientific, Waltham, MA, USA) was performed. Torrent Suite Software was used to pre-process the raw data, and base calling, alignment, coverage analysis and variant calling was performed using SeqNext software (JSI medical systems $\mathrm{GmbH}$ ) as reported previously [11]. According to international guidelines for clinical NGS panels [12], the minimal depth of coverage was set at 250 reads per tested amplicon. This to confidently identify also low frequency relevant variants in clinical tissues resulting from heterogeneity due to admixture of nonneoplastic cells, intratumoral variations (different clones) and viability of tumor cells. Relevant exons that are tested with this panel included KIT exons 8, 9, 11, 13, 14, 17 and PDGFR $\alpha$ exons 12, 14, 18 and BRAF codon 594, 599, 600 (www.moloncopath.nl).

\section{Computer 3D-modeling of the PDGFRa kinase domain}

Computer 3D-modeling of the activation loop in the kinase domain of PDGFR $\alpha$ was recently reported to stabilize the kinase in the inactive state and to facilitate the binding of imatinib. The crystal structure with the D842V mutation suggested activation of the kinase and kinetic data confirmed an increased affinity for ATP both in agreement with the observed drug resistance in patients with the D842V mutation [13]. To evaluate the possible consequences of the I843_D846del and M844 

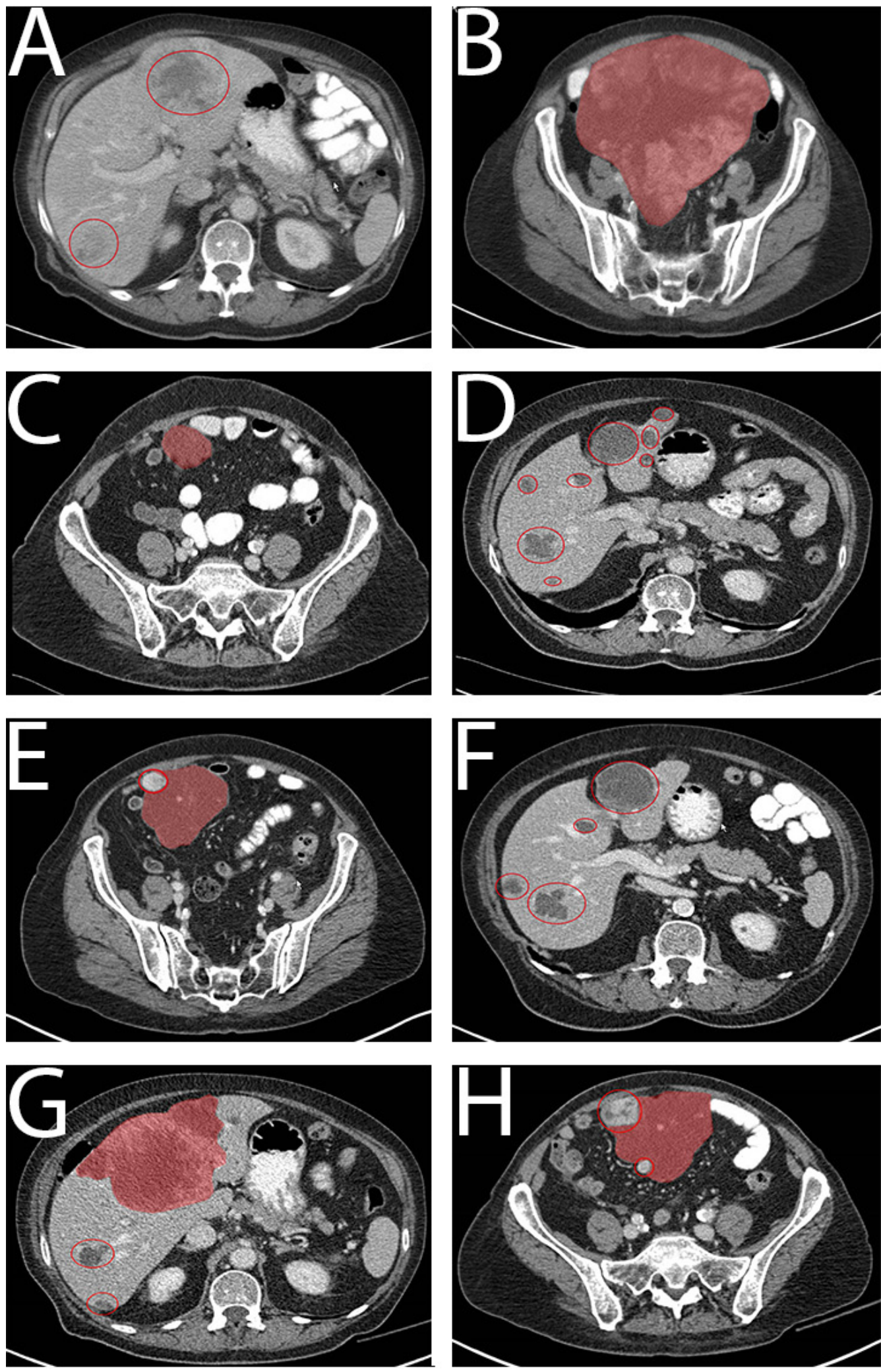

Figure 2: CT images of patient 2, left column images of pelvis, right column images of liver at the same time. Primary tumor (red area), metastases (red circles). A. Pretreatment, large tumor in the lower abdomen. B. Pretreatment, multiple liver metastases. C. 24 months imatinib, treatment response. D. 24 months imatinib, demarquation of metastases. E. 30 months imatinib, progressive tumor nodule (red circle). F. 30 months imatinib, progression liver metastases. G. 33 months, multiple progressive nodules (red circle). H. 33 months, progression of liver metastases. 
S847del variants on the activation loop of PDGFR $\alpha$, three 3D-models (PDGFR $\alpha$-D842V, PDGFR $\alpha$-M844_S847del and PDGFR $\alpha$ - I843_D846del) were built (Figure 4). The predicted orientation of D842, described to be essential for the auto-inhibited state of the tyrosine kinase domain [9], was conserved. The proposed hydrogen bond between D842 and H845(PDB; 4BKJ [14]) is almost certainly not formed, as the geometry of the interaction does not fall close to experimentally determined angular distributions [15]. Our 3D-modeling indicates that the PDGFR $\alpha$ M844 S847del and I843_D846del variants would play no role in activation.
In order to evaluate whether these 2 variants affect residues of PDGFR $\alpha$ that specifically interact with imatinib, the reported structure of the tyrosine kinase domain of DDR1 bound to imatinib (PDB; 4BKJ [14]) was used as template for homology modeling (35\% sequence identity) [16]. Our model predicts that imatinib interacts with the same amino acids of DDR1 (E672, T701, V763, H764, D784) that are conserved in PDGFR $\alpha$ (E644, T674, V815, H816, D836). Considering that the PDGFR $\alpha$ M844 S847del and I843 D846del variants do not affect these $\overline{5}$ residues, it is highly likely that these variants will not directly affect binding of imatinib or sunitinib.

A

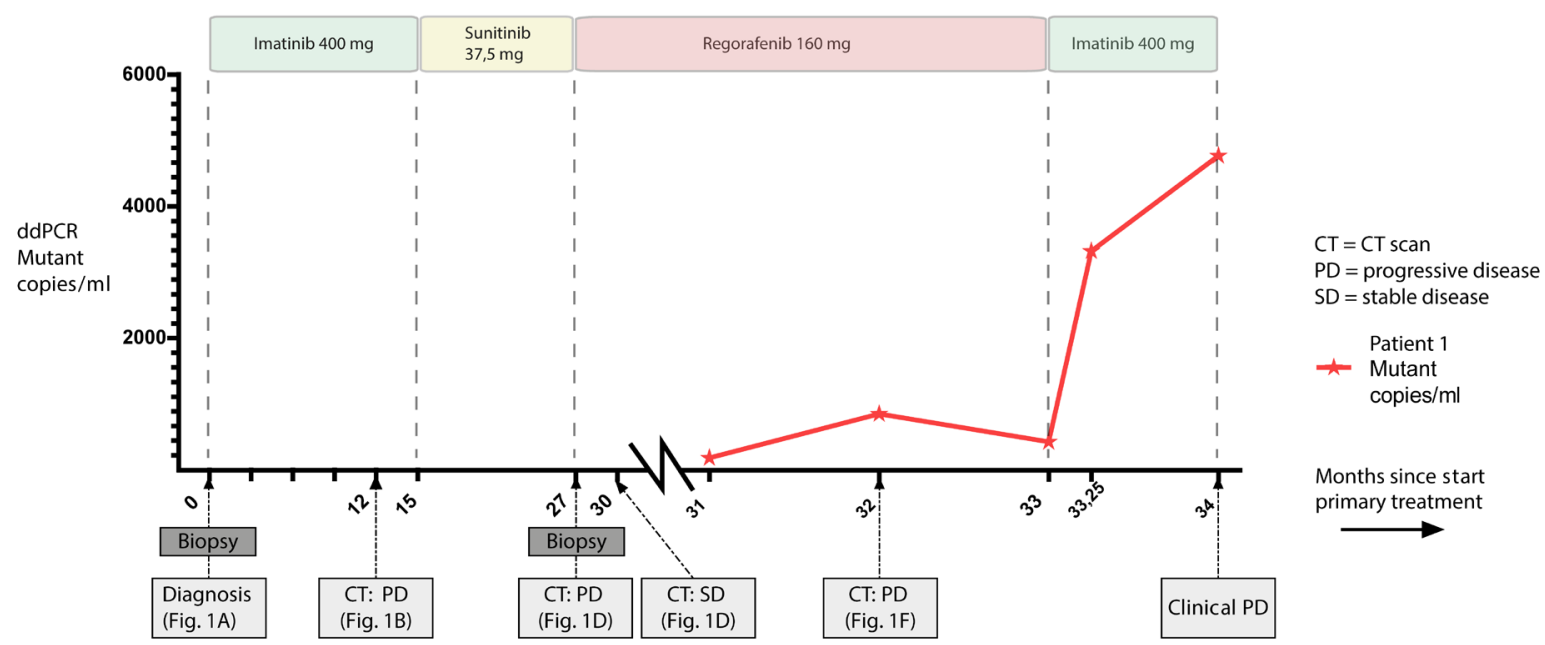

B

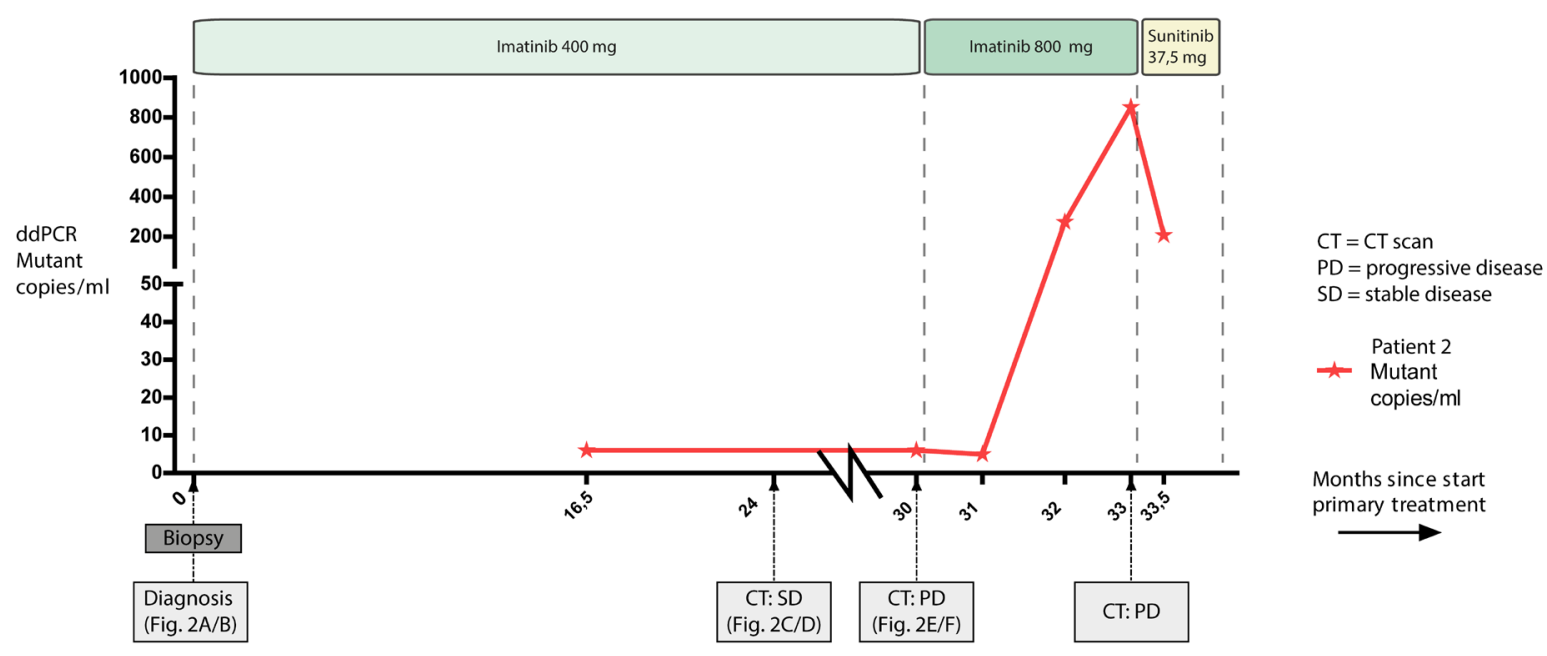

Figure 3: Serial plasma samples were analyzed during treatment. The PDGFR $\alpha$ mutant copies/ml level as tested with ddPCR are shown. A. Patient 1 with the p.M844-S847del; c.2531_2542del variant. First plasma samples was collected 31 months after start of treatment, disease progression as determined with CT after 32 months corresponded with a rise in mutant copies $/ \mathrm{ml}$. Patient died 33 months after start of first treatment. B. Patient 2 with the p.I843_D846del; c.2527_2538del variant. First plasma sample was collected 16,5 months after start of treatment, disease progression at 30 months was not detected in plasma ctDNA, however after switch of therapy an increase in mutant copies $/ \mathrm{ml}$ is detected corresponding with disease progression on CT at 32 months. After initiation of sunitinib, a decrease in mutant copies $\mathrm{ml}$ is seen. Patient died 36 months after initial diagnosis. 


\section{Analysis of circulating tumor DNA}

Blood samples were collected in EDTA tubes (vacutainer \#367525, Becton Dickinson, Franklin Lakes, NJ, USA) and processed within 4 hours after vena puncture. Samples were processed and isolation of DNA were performed as described elsewhere [17]. Digital droplet PCR (ddPCR) primers and probes was in-house designed and ordered at IDT (Coralville, IA, USA). The primer sequences for patient 1 (p.M844_S847del; c.2531_2542del) were Fwd. 5'-CTCCTGGCACAAGGAAA-3' (c.2473-c.2489) and Rev. 5'-GGACGTACACTGCCTTT-3' (c.2554-c.2570) resulting in a PCR product of 98 base pairs. The sequence of probe I (FAM) was 5'-GCCAGAGACATCAACTATGTGTCG-3' and probe II (HEX) 5'-CATGCATGATTCGAACTATGTGTCG-3'. For patient 2 (p.I843_D846del; c.2527_2538del) the primer sequences were ${ }^{-}$Fwd. 5'-ATTGTGAAGATCTGTGACTTTG-3' (position c.2491-c.2512) and Rev. 5'-AGTGAGGGAAGTGAGGA-3' (position c.2568-c.2584) resulting in a PCR product of 94 base pairs. The sequence of probe I (FAM) was 5'-GCCAGAGACTCGAACTATGTGTCG-3' and probe II (HEX) 5'-TGCATGATTCGAACTATGTGTCGAA-3'. Temperature gradient PCR of the primers and probes were performed to detect the optimal annealing temperature and resulted in an optimal PCR temperature of $55^{\circ} \mathrm{C}$ for both assays. The specific assays were validated on available tumor tissue. DdPCR was performed on a T100 Thermal Cycler (Bio-Rad, Hercules, CA, USA) and samples were transported to the QX200 Droplet Reader (Bio-Rad) for fluorescent measurement of FAM and HEX probes, data was analyzed with Quantasoft software version 1.6.6.

\section{REVIEW OF THE LITERATURE}

\section{PDGFR $\alpha$ mutations and response on imatinib}

PubMed was searched for articles concerning GIST patients with PDGFR $\alpha$ mutations and response to treatment with imatinib. Data of 14 papers and a total of

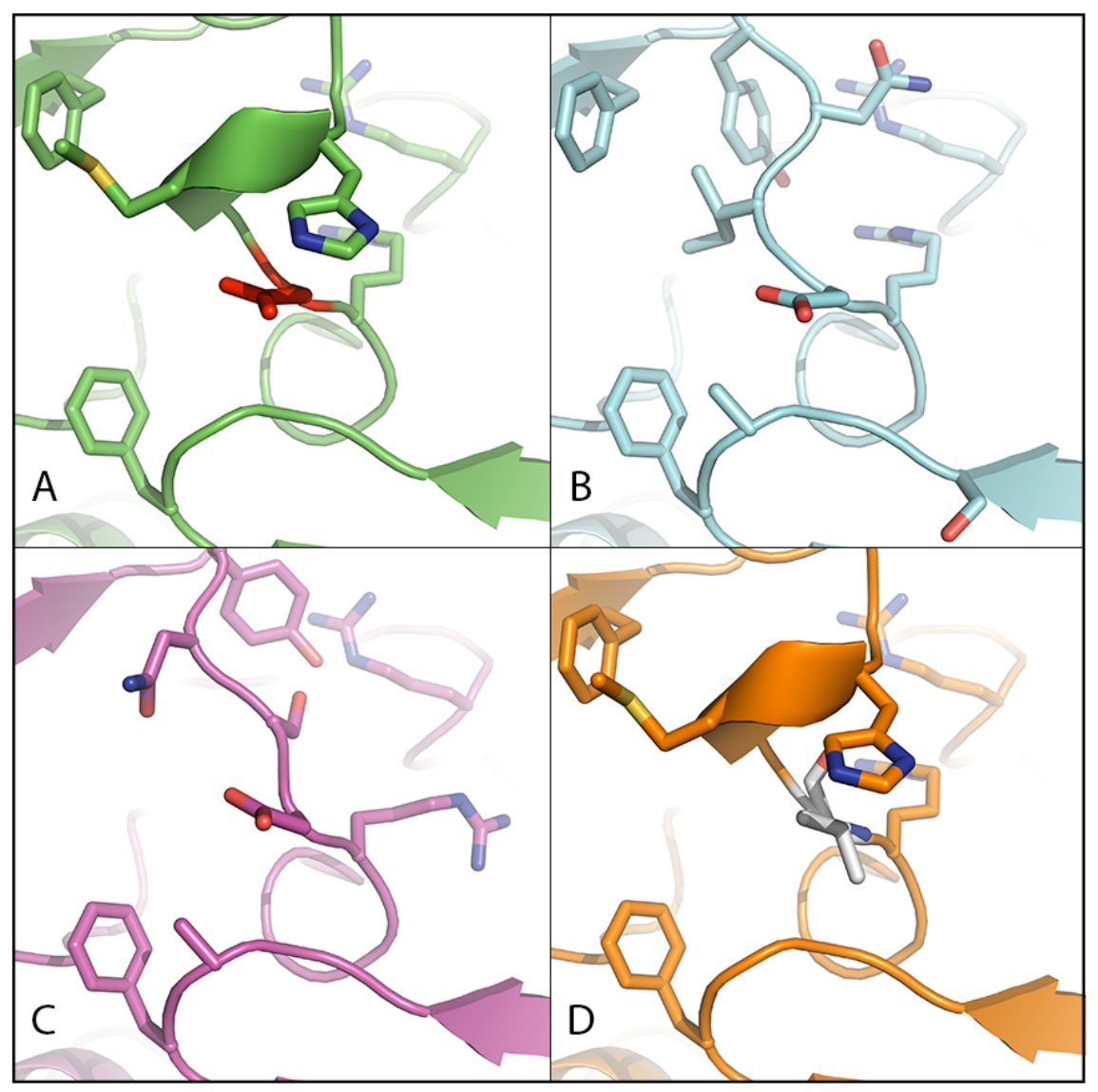

Figure 4: Residue 842 of human PDGFR $\alpha$. A. Residue D842 (in red) in the structure of wild type PDGFR $($ pdb 5K5X). B. Residue D842 in the structure of wild type PDGFR $\alpha$ modeled with variant M844_S847del. C. Residue D842 in the structure of wild type PDGFR $\alpha$ modeled with the I843_D846del variant. D. Residue V842 (in grey) in the structure of wild type PDGFR $\alpha$ modeled with mutation D842V. 
102 patients with PDGFR $\alpha$ exon 18 mutated GIST were retrieved by our search strategy (Figure 5).

Five of the fourteen papers describe data of progression free survival (PFS) or overall survival (OS) of patients with a PDGFR $\alpha$ mutated advanced GIST treated with imatinib (Table 1). A 10-fold increase in PFS is seen in patients with non-D842V mutated GIST compared with D842V mutated who were treated with imatinib. Recently, a series of 823 GIST patients including 13 patients with a PDGFR $\alpha$ exon 18 mutated GIST who were treated with first line imatinib is described [18]. The OS of patients with a D842V mutation was 25.2 months compared to 59.8 months for patients with a non-D842V PDGFR $\alpha$ mutated GIST $(p=0.02)$. At least two other studies showed a better median OS in patients with a non-D842V PDGFR $\alpha$ mutation compared to patients with a D842V mutation $[18,19]$.

In COSMIC (catalogue of somatic mutations in cancer; www.cancer.sanger.ac.uk/cosmic) the p.M844 S847del mutation is described in eight patients in five studies. All patients were treated surgically and had no evidence of disease or recurrence afterwards, so no information was reported regarding the response on treatment (Table 2).

A few patients with a GIST with a p.I843_D846del mutation have been described, although information regarding the response to TKI treatment is scarce $[20,37$ 47].

\section{Response on sunitinib as second line treatment}

Two papers report on response to second-line treatment with sunitinib. In nine patients, no objective response was seen [18]. Patients with the D842V mutation tended to show poorer PFS than those with nonD842V PDGFR $\alpha$ mutations (median PFS 1.9 months for D842V mutant vs. 7.3 months for non-D842V PDGFR $\alpha$ mutations; $\mathrm{P}=0.26$ ). Another cohort consisted of 11 patients with a PDGFR $\alpha$ mutated GIST [20]. Of those patients, three had disease stabilization for more than 6 months. No significant difference could be shown between the different PDGFR $\alpha$ mutations (PFS 2.1 months for D842V mutant and 7.8 months for other mutations, $\mathrm{P}=$ $0.2489)$.

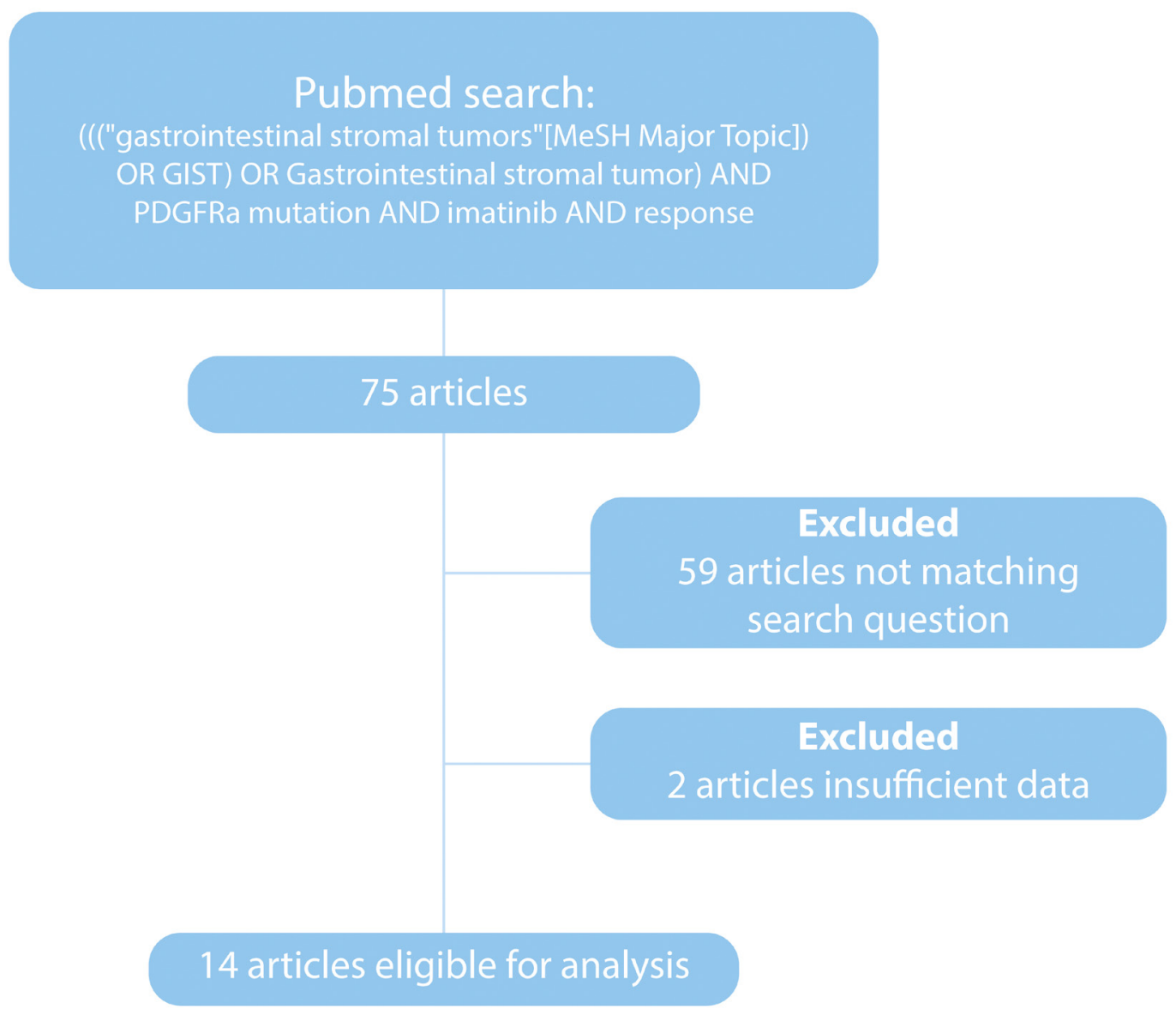

Figure 5: Flow-chart of search strategy. In total 61 articles were excluded because of other study questions or insufficient data, resulting in 14 papers eligible for analysis. 
Table 1: Patient numbers and survival data of 14 papers found by the performed literature search.

\begin{tabular}{|c|c|c|c|c|c|c|c|}
\hline Author & Year & $\begin{array}{l}\text { Patients } \\
\text { (\% PDGFRA) }\end{array}$ & $\begin{array}{l}\text { PDGFRA } \\
\text { exon } 18 \\
\text { (D842V) }\end{array}$ & $\begin{array}{l}\text { PFS non- } \\
\text { D842V }\end{array}$ & $\begin{array}{l}\text { PFS } \\
\text { D842V }\end{array}$ & OS non-D842V & OS D842V \\
\hline Yoo [18] & 2015 & $823(2 \%)$ & $13(9)$ & $29.5 \mathrm{~m}$ & $3.8 \mathrm{~m}$ & $59.8 \mathrm{~m}$ & $25.2 \mathrm{~m}$ \\
\hline Cassier [20] & 2012 & 58 & $49(32)$ & $28.5 \mathrm{~m}$ & $2.8 \mathrm{~m}$ & NR (46 m fu) & $14.7 \mathrm{~m}$ \\
\hline Valadao [21] & 2012 & $60(5 \%)$ & 3 & $*$ & $*$ & $*$ & * \\
\hline Kang [22] & 2012 & $290(1 \%)$ & $3(2)$ & SD & PD & $*$ & $*$ \\
\hline Yoon [23] & 2012 & $88(5 \%)$ & $4(3)$ & $*$ & $*$ & $*$ & * \\
\hline Dileo [24] & 2011 & 2 & $1(0)$ & $29 \mathrm{~m}$ & * & * & * \\
\hline Kim [25] & 2009 & $113(1 \%)$ & $1(0)$ & SD & $*$ & $*$ & $*$ \\
\hline Ryu [26] & 2009 & $47(0 \%)$ & 0 & $*$ & $*$ & $*$ & $*$ \\
\hline Heinrich [27] & 2008 & $746(1 \%)$ & $8(4)$ & $*$ & * & $>12 \mathrm{~m}(\operatorname{med} 40,8)$ & $9.7 \mathrm{~m}$ \\
\hline $\operatorname{Lim}[28]$ & 2008 & $12(0 \%)$ & 0 & $*$ & $*$ & * & * \\
\hline Gomes [29] & 2008 & $78(4 \%)$ & $3(2)$ & $*$ & $*$ & $*$ & $*$ \\
\hline Debiec - Rychter [30] & 2004 & $39(5 \%)$ & $2(3)$ & * & * & * & * \\
\hline Heinrich [31] & 2003 & $127(5 \%)$ & $6(3)$ & $*$ & $*$ & $*$ & * \\
\hline Heinrich [32] & 2003 & $40(28 \%)$ & $11(6)$ & $*$ & $*$ & $*$ & $*$ \\
\hline
\end{tabular}

$\mathrm{NR}=$ not reached, $\mathrm{PD}=$ progressive disease, $\mathrm{SD}=$ stable disease, $\mathrm{m}=$ month, fu $=$ follow up

Table 2: Overview of the literature regarding p.M844_S847 PDGFRa deletion

\begin{tabular}{|c|c|c|c|c|c|}
\hline Author & Patients & Location & Risk category & Clinical features & $\begin{array}{l}\text { Response } \\
\text { imatinib }\end{array}$ \\
\hline Lasota [4] & 1 & - & - & Not reported & Not reported \\
\hline Sihto [33] & 1 & Stomach & Intermediate & Not reported & Not reported \\
\hline Chang [34] & 1 & Stomach & High & No recurrence $(19 m)$ & Not reported \\
\hline Silva [35] & 2 & Stomach & Low & No recurrence* & Not reported \\
\hline \multirow[t]{3}{*}{ Kang [36] } & 3 & Stomach & High & No recurrence* & Not reported \\
\hline & & Stomach & Very low & No recurrence* & Not reported \\
\hline & & Stomach & High & No recurrence* & Not reported \\
\hline
\end{tabular}

* Follow up time is not reported

\section{DISCUSSION}

Our two case patients with a non-D842V PDGFR $\alpha$ mutation responded or had prolonged periods of nonprogressive disease to various tyrosine kinase inhibitors. Although patients with advanced disease and a PDGFR $\alpha$ mutation can respond to treatment with imatinib, the overall survival of these patients is worse than that of patients with a KIT mutation bearing GIST. This is reported in studies with advanced GIST patients where a median survival of 57 months for patients expressing KIT compared to a median overall survival of 23.7 months for patients with a PDGFR $\alpha$ mutation is reached [20, 48]. Imatinib resistance was reported most frequently in GIST patients with PDGFR $\alpha$ mutations and wild type GISTs. However, the PDGFR $\alpha$ mutations were not specified [49]. In contrast to the mutation distribution described in literature of $10 \%$ PDGFR $\alpha$ mutations in GIST, most articles report a much lower fraction of patients with
PDGFR $\alpha$ mutations, suggesting underreporting.

To our knowledge, this is the first report regarding a p.M844_S847del variant in relation to TKI treatment. We show the clinical importance of mutation detection as patients with specific PDGFR $\alpha$ mutations respond well on imatinib treatment. The published reports that were found in the PubMed search provide limited PFS and OS data. However, patients with a non-D842V mutation have a favorable prognosis when treated with imatinib compared to patients with a D842V PDGFR $\alpha$ mutated GIST. A recent report showed a better overall survival in patients with non-D842V when treated with imatinib compared to patients with D842V mutated tumors [18]. Due to the latter it is of great importance to differentiate between those.

The frequency of recurrence after surgery is lower in patients with gastric versus non-gastric PDGFR $\alpha$ mutated GIST, similar to patients with other mutations [50]. In metastatic D842V mutated GIST the role of TKI 
is very limited and the prognosis is clearly far inferior to other mutated GISTs [51, 52]. Several new therapies are being investigated for patients with a PDGFR $\alpha$ (D842V) mutation [27, 53], however none of them are already available for daily clinical practice.

TKI sensitive mutations are mostly located near the imatinib resistant $\mathrm{D} 842 \mathrm{~V}$ domain. It has been implied that primary resistance to imatinib correlates specifically with substitution mutations that affect residue D842 of the kinase activation loop [9]. Modifications of this domain are interfering with a swinging movement of the activation loop. This movement is linked to a conformational shift of the ATP binding pocket from an "open" or active setup to a "closed" or inactive set-up. Since imatinib is an ATP competitor and binds exclusively to the closed form of the kinase, substitutions of PDGFR $\alpha$ D842 reduce the accessibility of the ATP pocket and thereby give relative resistance to the drug [13]. An increased affinity for ATP of the mutated tyrosine kinase domain has also been reported to contribute to the acquired resistance to imatinib [54]. In contrast to $\mathrm{D} 842 \mathrm{~V}$, our 3D-modeling of the kinase activation loop indicates that the M844 S847del and I843 D846del variants would play no role in activation. In addition, homology modeling predicted that imatinib interacts with 5 residues in PDGFR $\alpha$ (E644, T674, V815, H816, D836) conserved with those in DDR1. Because the PDGFR $\alpha$ M844_S847del and I843_D846del variants do not affect these 5 residues, it is highly likely that these variants will not directly affect binding of imatinib or sunitinib. In summary, our 3D-modeling analysis indicates that PDGFR $\alpha$ proteins harboring the M844_S847del and I843 D846del variants would not directly interfere in imatinib or sunitinib binding and would not affect activity. Consequently, both variants would still allow binding and inhibition of imatinib and sunitinib. This is in good agreement with the observed response to imatinib in these two patients. However, to assess sensitivity to tyrosine kinase inhibitors of these particular mutations, cell linebased drug sensitivity analysis would be of added value.

Secondary resistance usually occurs between 6-24 months after start of imatinib treatment. Secondary mutations as cause of TKI insensitivity have been found in patients with primary KIT mutations and rarely in patients with primary PDGFR $\alpha$ mutations [5]. Alternative pathways for secondary resistance are activation of other growth pathways and loss of the remaining wildtype PDGFR $\alpha$ and overexpression of PDGFR $\alpha$ or other tyrosine kinase receptors [55]. In patient 1, a biopsy at progression was taken. However, in addition to the M844 S847del variant in exon 18 of PDGFR $\alpha$, no secondary treatment resistant mutations were detected with NGS.

The detection of mutations in circulating tumor DNA from cell free plasma (ctDNA) of patients with GIST has been reported before [56-60]. In this study we report on the correlation between clinical course/treatment response and the detection of the tumor-specific PDGFRA mutations in ctDNA of serially taken blood samples of these 2 patients with GIST, showing the use of mutation detection in ctDNA in plasma to monitor treatment response. In patient 1 , the clinical course correlated well with the ctDNA level. However, in patient 2 the moment of progression on first line treatment was not detected in the ctDNA. According to the CT scan at 30 months (Figure 2E/F) there is one progressive nodule detected implying treatment resistance. Some lesions became larger, but have a cystic aspect what in GIST could match with treatment response. Since there is little active tumor tissue, we suggest the limited DNA shed of the progressive nodule in this phase is below the detection level of ddPCR. The following CT scan (Figure 2G/H) shows massive progression which is preceded by a detectable rise in mutant ctDNA copies. Further research has to reveal the clinical value of detectable mutant ctDNA copies.

In conclusion, the p.M844_S847del and p.I843 D846del mutations are rare but have clinical importance since these specific mutations are associated by a response to treatment with TKIs. This report emphasizes the importance of mutational analysis of tumors and is exemplary for the implementation of personalized medicine. Mutational analysis should be performed of each primary and resistant tumor to increase the knowledge of primary and secondary resistant mutations. Mutation detection in ctDNA to assess treatment response seems feasible. We suggest to register patients with very uncommon genetic aberrations in a prospective international database to understand the tumor biology and obtain more evidence to predict treatment response and eventually contributing to the development of new targeted therapies.

\section{GRANT SUPPORT}

$\mathrm{PAB}$ works on a research grant provided by the Dutch Cancer Society (KWF, Alpe D'HuZes research grant RUG 2013-6355).

\section{CONFLICTS OF INTEREST}

The authors declared no conflicts of interest.

\section{REFERENCES}

1. Demetri GD, von Mehren M, Antonescu CR, DeMatteo RP, Ganjoo KN, Maki RG, Pisters PW, Raut CP, Riedel RF, Schuetze S, Sundar HM, Trent JC, Wayne JD. NCCN Task Force report: update on the management of patients with gastrointestinal stromal tumors. J Natl Compr Canc Netw. 2010;8:S1-S41.

2. Miettinen M, Lasota J. Gastrointestinal stromal tumors: review on morphology, molecular pathology, prognosis, and differential diagnosis. Arch Pathol Lab Med. 2006; 130: 
1466-1478.

3. Hirota S, Isozaki K, Moriyama Y, Hashimoto K, Nishida T, Ishiguro S, Kawano K, Hanada M, Kurata A, Takeda M, Muhammad Tunio G, Matsuzawa Y, Kanakura Y, et al. Gain-of-function mutations of c-kit in human gastrointestinal stromal tumors. Science. 1998; 279: 577 580 .

4. Lasota J, Dansonka-Mieszkowska A, Sobin LH, Miettinen M. A great majority of GISTs with PDGFRA mutations represent gastric tumors of low or no malignant potential. Lab Invest. 2004; 84: 874-883.

5. Antonescu CR, Besmer P, Guo T, Arkun K, Hom G, Koryotowski B, Leversha MA, Jeffrey PD, Desantis D, Singer S, Brennan MF, Maki RG, DeMatteo RP. Acquired resistance to imatinib in gastrointestinal stromal tumor occurs through secondary gene mutation. Clin Cancer Res. 2005; 11: 4182-4190.

6. Demetri GD, Reichardt P, Kang YK, Blay JY, Rutkowski $\mathrm{P}$, Gelderblom H, Hohenberger P, Leahy M, von Mehren M, Joensuu H, Badalamenti G, Blackstein M, Le Cesne $A$, et al, and GRID study investigators. Efficacy and safety of regorafenib for advanced gastrointestinal stromal tumours after failure of imatinib and sunitinib (GRID): an international, multicentre, randomised, placebo-controlled, phase 3 trial. Lancet. 2013; 381: 295-302.

7. Gao J, Tian Y, Li J, Sun N, Yuan J, Shen L. Secondary mutations of c-KIT contribute to acquired resistance to imatinib and decrease efficacy of sunitinib in Chinese patients with gastrointestinal stromal tumors. Med Oncol. 2013; 30:522.

8. Joensuu H, Rutkowski P, Nishida T, Steigen SE, Brabec P, Plank L, Nilsson B, Braconi C, Bordoni A, Magnusson MK, Sufliarsky J, Federico M, Jonasson JG, et al. KIT and PDGFRA mutations and the risk of GI stromal tumor recurrence. J Clin Oncol. 2015; 33: 634-642.

9. Corless CL, Schroeder A, Griffith D, Town A, McGreevey L, Harrell P, Shiraga S, Bainbridge T, Morich J, Heinrich MC. PDGFRA mutations in gastrointestinal stromal tumors: frequency, spectrum and in vitro sensitivity to imatinib. J Clin Oncol. 2005; 23: 5357-5364.

10. Crowley E, Di Nicolantonio F, Loupakis F, Bardelli A. Liquid biopsy: monitoring cancer-genetics in the blood. Nat Rev Clin Oncol. 2013; 10: 472-484.

11. Boleij A, Tops BB, Rombout PD, Dequeker EM, Ligtenberg MJ, van Krieken JH; Dutch RAS EQA Initiative. RAS testing in metastatic colorectal cancer: excellent reproducibility amongst 17 Dutch pathology centers. Oncotarget. 2015; 6:15681-689. https://doi.org/10.18632/ oncotarget. 3804 .

12. Jennings LJ, Arcila ME, Corless C, Kamel-Reid S, Lubin IM, Pfeifer J, Temple-Smolkin RL, Voelkerding $\mathrm{KV}$, Nikiforova MN. Guidelines for Validation of NextGeneration Sequencing-Based Oncology Panels: A Joint Consensus Recommendation of the Association for Molecular Pathology and College of American Pathologists.
J Mol Diagn. 2017; 19: 341-365.

13. Gounder MM, Maki RG. Molecular basis for primary and secondary tyrosine kinase inhibitor resistance in gastrointestinal stromal tumor. Cancer Chemother Pharmacol. 2011; 67:S25-43.

14. Canning P, Tan L, Chu K, Lee SW, Gray NS, Bullock AN. Structural mechanisms determining inhibition of the collagen receptor DDR1 by selective and multi-targeted type II kinase inhibitors. J Mol Biol. 2014; 426: 2457-2470.

15. Engh RA, Huber R. Accurate bond and angle parameters for X-ray protein structure refinement. Acta Crystallogr. 1991; A47: 392-400.

16. Biasini M, Bienert S, Waterhouse A, Arnold K, Studer G, Schmidt T, Kiefer F, Gallo Cassarino T, Bertoni M, Bordoli L, Schwede T. SWISS-MODEL: modelling protein tertiary and quaternary structure using evolutionary information. Nucleic Acids Res. 2014; 42:W252-8.

17. Boonstra PA, Tibbesma M, Bosman LJ, Mathijssen RHJ, van Coevorden F, Steeghs N, Suurmeijer AJH, ter Elst A, Gietema JA, Reyners AKL, Schuuring EMD, Dutch GIST Consortium. Abstract 3107: A single ddPCR assay to detect KIT exon 11 mutations in tumor and cell free plasma DNA of patients with gastrointestinal stromal tumors. Cancer Res. 2016; 76: Supplement. https://doi.org/10.1158/15387445.AM2016-3107.

18. Yoo C, Ryu MH, Jo J, Park I, Ryoo BY, Kang YK. Efficacy of Imatinib in Patients with Platelet-derived Growth Factor Receptor Alpha-mutated Gastrointestinal Stromal Tumors. Cancer Res Treat. 2016; 48:546-52.

19. Heinrich MC, Owzar K, Corless CL, Hollis D, Borden EC, Fletcher CD, Ryan CW, von Mehren M, Blanke CD, Rankin C, Benjamin RS, Bramwell VH, Demetri GD, et al. Correlation of kinase genotype and clinical outcome in the North American Intergroup Phase III Trial of imatinib mesylate for treatment of advanced gastrointestinal stromal tumor: CALGB 150105 Study by Cancer and Leukemia Group B and Southwest Oncology Group. J Clin Oncol. 2008; 26: 5360-5367.

20. Cassier PA, Fumagalli E, Rutkowski P, Schoffski P, Van Glabbeke M, Debiec-Rychter M, Emile JF, Duffaud F, Martin-Broto J, Landi B, Adenis A, Bertucci F, Bompas $\mathrm{E}$, et al. Outcome of patients with platelet-derived growth factor receptor alpha-mutated gastrointestinal stromal tumors in the tyrosine kinase inhibitor era. Clin Cancer Res. 2012; 18:4458-64.

21. Valadao M, Braggio D, Santos AF, Pimenta-Inada HK, Linhares E, Goncalves R, Romano S, Vilhena B, Small I, Cubero D, Cruz F, Oliveira AT, Martinho O, et al. Involvement of signaling molecules in the prediction of response to imatinib treatment in metastatic GIST patients. J Surg Res. 2012; 178: 288-293.

22. Kang HJ, Ryu MH, Kim KM, Park YS, Choi J, Ryoo BY, Kim WH, Im SA, Bang YJ, Park SH, Lee JH, Chung IJ, Bae $\mathrm{HI}$, et al. Imatinib efficacy by tumor genotype in Korean patients with advanced gastrointestinal stromal tumors 
(GIST): The Korean GIST Study Group (KGSG) study. Acta Oncol. 2012; 51: 528-536.

23. Yoon DH, Ryu MH, Ryoo BY, Beck M, Choi DR, Cho Y, Lee JL, Chang HM, Kim TW, Kang YK. Sunitinib as a second-line therapy for advanced GISTs after failure of imatinib: relationship between efficacy and tumor genotype in Korean patients. Invest New Drugs. 2012; 30: 819-827.

24. Dileo P, Pricl S, Tamborini E, Negri T, Stacchiotti S, Gronchi A, Posocco P, Laurini E, Coco P, Fumagalli E, Casali PG, Pilotti S. Imatinib response in two GIST patients carrying two hitherto functionally uncharacterized PDGFRA mutations: an imaging, biochemical and molecular modeling study. Int J Cancer. 2011; 128: 983990.

25. Kim TW, Ryu MH, Lee H, Sym SJ, Lee JL, Chang HM, Park YS, Lee KH, Kang WK, Shin DB, Bang YJ, Lee JS, Kang YK. Kinase mutations and efficacy of imatinib in Korean patients with advanced gastrointestinal stromal tumors. Oncologist. 2009; 14: 540-547.

26. Ryu MH, Kang WK, Bang YJ, Lee KH, Shin DB, Ryoo BY, Roh JK, Kang JH, Lee H, Kim TW, Chang HM, Park JO, Park YS, et al. A prospective, multicenter, phase 2 study of imatinib mesylate in korean patients with metastatic or unresectable gastrointestinal stromal tumor. Oncology. 2009; 76: 326-332.

27. Heinrich MC, Griffith D, McKinley A, Patterson J, Presnell A, Ramachandran A, Debiec-Rychter M. Crenolanib inhibits the drug-resistant PDGFRA D842V mutation associated with imatinib-resistant gastrointestinal stromal tumors. Clin Cancer Res. 2012; 18: 4375-4384.

28. Lim KH, Huang MJ, Chen LT, Wang TE, Liu CL, Chang CS, Liu MC, Hsieh RK, Tzen CY. Molecular analysis of secondary kinase mutations in imatinib-resistant gastrointestinal stromal tumors. Med Oncol. 2008; 25: 207 213.

29. Gomes AL, Gouveia A, Capelinha AF, de la Cruz D, Silva P, Reis RM, Pimenta A, Lopes JM. Molecular alterations of KIT and PDGFRA in GISTs: evaluation of a Portuguese series. J Clin Pathol. 2008; 61: 203-208.

30. Debiec-Rychter M, Dumez H, Judson I, Wasag B, Verweij J, Brown M, Dimitrijevic S, Sciot R, Stul M, Vranck H, Scurr M, Hagemeijer A, van Glabbeke M, van Oosterom AT, and EORTC Soft Tissue and Bone Sarcoma Group. Use of c-KIT/PDGFRA mutational analysis to predict the clinical response to imatinib in patients with advanced gastrointestinal stromal tumours entered on phase I and II studies of the EORTC Soft Tissue and Bone Sarcoma Group. Eur J Cancer. 2004; 40:689-95.

31. Heinrich MC, Corless CL, Demetri GD, Blanke CD, von Mehren M, Joensuu H, McGreevey LS, Chen CJ, Van den Abbeele AD, Druker BJ, Kiese B, Eisenberg B, Roberts PJ, et al. Kinase mutations and imatinib response in patients with metastatic gastrointestinal stromal tumor. J Clin Oncol. 2003; 21 : 4342-4349.

32. Heinrich MC, Corless CL, Duensing A, McGreevey L,
Chen CJ, Joseph N, Singer S, Griffith DJ, Haley A, Town A, Demetri GD, Fletcher CD, Fletcher JA. PDGFRA activating mutations in gastrointestinal stromal tumors. Science. 2003; 299: 708-710.

33. Sihto H, Franssila K, Tanner M, Vasama-Nolvi C, Sarlomo-Rikala M, Nupponen NN, Joensuu H, Isola J. Platelet-derived growth factor receptor family mutations in gastrointestinal stromal tumours. Scand J Gastroenterol. 2006; 41: 805-811.

34. Chang HM, Ryu MH, Lee H, Jang SJ, Lee JL, Kim TW, Yook JH, Oh ST, Kim BS, Lee JS, Kang YK. PDGFRalpha gene mutation and protein expression in gastrointestinal stromal tumors. Oncology. 2008; 74: 88-95.

35. Silva M, Veiga I, Ribeiro FR, Vieira J, Pinto C, Pinheiro M, Mesquita B, Santos C, Soares M, Dinis J, Santos L, Lopes $\mathrm{P}$, Afonso $\mathrm{M}$, et al. Chromosome copy number changes carry prognostic information independent of KIT/PDGFRA point mutations in gastrointestinal stromal tumors. BMC Med. 2010; 8: 26-7015-8-26.

36. Kang GH, Srivastava A, Kim YE, Park HJ, Park CK, Sohn TS, Kim S, Kang DY, Kim KM. DOG1 and PKC- $\theta$ are useful in the diagnosis of KIT-negative gastrointestinal stromal tumors. Mod Pathol. 2011; 24:866-75.

37. Origone P, Gargiulo S, Mastracci L, Ballestrero A, Battistuzzi L, Casella C, Comandini D, Cusano R, Dei Tos AP, Fiocca R, Garuti A, Ghiorzo P, Martinuzzi C, et al. Molecular characterization of an Italian series of sporadic GISTs. Gastric Cancer. 2013; 16: 596-601.

38. Chou A, Chen J, Clarkson A, Samra JS, Clifton-Bligh RJ, Hugh TJ, Gill AJ. Succinate dehydrogenase-deficient GISTs are characterized by IGF1R overexpression. Mod Pathol. 2012; 25:1307-13.

39. Calabuig-Farinas S, Lopez-Guerrero JA, Navarro S, Machado I, Poveda A, Pellin A, Llombart-Bosch A. Evaluation of prognostic factors and their capacity to predict biological behavior in gastrointestinal stromal tumors. Int J Surg Pathol. 2011; 19: 448-461.

40. Mendoza Y, Singh C, Castillo Mewa J, Fonseca E, Smith $\mathrm{R}$, Pascale JM. Beginning of personalized medicine in Panama: Molecular and pathological characteristics of gastrointestinal stromal tumors from archival paraffinembedded tissue. Oncol Lett. 2011; 2: 941-947.

41. Sapi Z, Fule T, Hajdu M, Matolcsy A, Moskovszky L, Mark A, Sebestyen A, Bodoky G. The activated targets of mTOR signaling pathway are characteristic for PDGFRA mutant and wild-type rather than KIT mutant GISTs. Diagn Mol Pathol. 2011; 20: 22-33.

42. Yamamoto H, Kojima A, Nagata S, Tomita Y, Takahashi S, Oda Y. KIT-negative gastrointestinal stromal tumor of the abdominal soft tissue: a clinicopathologic and genetic study of 10 cases. Am J Surg Pathol. 2011; 35: 1287-1295.

43. Arne G, Kristiansson E, Nerman O, Kindblom LG, Ahlman $\mathrm{H}$, Nilsson B, Nilsson O. Expression profiling of GIST: CD133 is associated with KIT exon 11 mutations, gastric 
location and poor prognosis. Int J Cancer. 2011; 129: 11491161.

44. Miettinen M, Wang ZF, Lasota J. DOG1 antibody in the differential diagnosis of gastrointestinal stromal tumors: a study of 1840 cases. Am J Surg Pathol. 2009; 33: 14011408 .

45. Ostrowski J, Polkowski M, Paziewska A, Skrzypczak M, Goryca K, Rubel T, Kokoszynska K, Rutkowski P, Nowecki ZI, Vel Dobosz AJ, Jarosz D, Ruka W, Wyrwicz LS. Functional features of gene expression profiles differentiating gastrointestinal stromal tumours according to KIT mutations and expression. BMC Cancer. 2009; 9:413.

46. Kontogianni-Katsarou K, Dimitriadis E, Lariou C, KairiVassilatou E, Pandis N, Kondi-Paphiti A. KIT exon 11 codon 557/558 deletion/insertion mutations define a subset of gastrointestinal stromal tumors with malignant potential. World J Gastroenterol. 2008; 14: 1891-1897.

47. Mazzola P, Spitale A, Banfi S, Mazzucchelli L, Frattini M, Bordoni A. Epidemiology and molecular biology of gastrointestinal stromal tumors (GISTs): a populationbased study in the South of Switzerland, 1999-2005. Histol Histopathol. 2008; 23: 1379-1386.

48. Blanke CD, Demetri GD, von Mehren M, Heinrich MC, Eisenberg B, Fletcher JA, Corless CL, Fletcher CD, Roberts PJ, Heinz D, Wehre E, Nikolova Z, Joensuu H. Long-term results from a randomized phase II trial of standard- versus higher-dose imatinib mesylate for patients with unresectable or metastatic gastrointestinal stromal tumors expressing KIT. J Clin Oncol. 2008; 26: 620-625.

49. Lee JH, Kim Y, Choi JW, Kim YS. Correlation of imatinib resistance with the mutational status of KIT and PDGFRA genes in gastrointestinal stromal tumors: a meta-analysis. J Gastrointestin Liver Dis. 2013; 22: 413-418.

50. Wozniak A, Rutkowski P, Schoffski P, Ray-Coquard I, Hostein I, Schildhaus HU, Le Cesne A, Bylina E, Limon J, Blay JY, Siedlecki JA, Wardelmann E, Sciot R, et al. Tumor genotype is an independent prognostic factor in primary gastrointestinal stromal tumors of gastric origin: a european multicenter analysis based on ConticaGIST. Clin Cancer Res. 2014; 20: 6105-6116.

51. Braggio E, Braggio DA, Small IA, Lopes LF, Valadão M, Gouveia ME, Moreira AS, Linhares E, Romano S, Bacchi CE, Renault IZ, Guimarães DP, Ferreira CG. Prognostic relevance of KIT and PDGFRA mutations in gastrointestinal stromal tumors. Anticancer Res. 2010; 30:2407-14.
52. Hou YY, Grabellus F, Weber F, Zhou Y, Tan YS, Li J, Shen KT, Qin J, Sun YH, Qin XY, Bockhorn M, Gerken $\mathrm{G}$, Broelsch CE, et al. Impact of KIT and PDGFRA gene mutations on prognosis of patients with gastrointestinal stromal tumors after complete primary tumor resection. J Gastrointest Surg. 2009; 13: 1583-1592.

53. Weisberg E, Wright RD, Jiang J, Ray A, Moreno D, Manley PW, Fabbro D, Hall-Meyers E, Catley L, Podar K, Kung AL, Griffin JD. Effects of PKC412, nilotinib, and imatinib against GIST-associated PDGFRA mutants with differential imatinib sensitivity. Gastroenterology. 2006; 131: 17341742.

54. Liang L, Yan XE, Yin Y, Yun CH. Structural and biochemical studies of the PDGFRA kinase domain. Biochem Biophys Res Commun. 2016; 477: 667-672.

55. Gramza AW, Corless CL, Heinrich MC. Resistance to Tyrosine Kinase Inhibitors in Gastrointestinal Stromal Tumors. Clin Cancer Res. 2009; 15: 7510-7518.

56. Maier J, Lange $\mathrm{T}$, Kerle I, Specht $\mathrm{K}$, Bruegel $\mathrm{M}$, Wickenhauser C, Jost P, Niederwieser D, Peschel C, Duyster J, von Bubnoff N. Detection of mutant free circulating tumor DNA in the plasma of patients with gastrointestinal stromal tumor harboring activating mutations of CKIT or PDGFRA. Clin Cancer Res. 2013; 19: 4854-4867.

57. Kang G, Sohn BS, Pyo JS, Kim JY, Lee B, Kim KM. Detecting Primary KIT Mutations in Presurgical Plasma of Patients with Gastrointestinal Stromal Tumor. Mol Diagn Ther. 2016; 20: 347-351.

58. Kang G, Bae BN, Sohn BS, Pyo JS, Kang GH, Kim KM. Detection of KIT and PDGFRA mutations in the plasma of patients with gastrointestinal stromal tumor. Target Oncol. 2015; 10: 597-601.

59. Wada N, Kurokawa Y, Takahashi T, Hamakawa T, Hirota S, Naka T, Miyazaki Y, Makino T, Yamasaki M, Nakajima K, Takiguchi S, Mori M, Doki Y. Detecting Secondary C-KIT Mutations in the Peripheral Blood of Patients with Imatinib-Resistant Gastrointestinal Stromal Tumor. Oncology. 2016; 90: 112-117.

60. Yoo C, Ryu MH, Na YS, Ryoo BY, Park SR, Kang YK. Analysis of serum protein biomarkers, circulating tumor DNA, and dovitinib activity in patients with tyrosine kinase inhibitor-refractory gastrointestinal stromal tumors. Ann Oncol. 2014; 25: 2272-2277. 